\title{
Fabrication and Spectral Properties of Wood-Based Luminescent Nanocomposites
}

\author{
Xianjun Li, ${ }^{1}$ Yun Li, ${ }^{1}$ Yongfeng Luo, ${ }^{2}$ Qunying Mou, ${ }^{2}$ Xingong Li, \\ Lisheng $\mathrm{Xie},{ }^{1}$ and Yiqiang $\mathrm{Wu}^{1}$ \\ ${ }^{1}$ Material Science and Engineering College, Central South University of Forestry and Technology, Changsha, Hunan 410004, China \\ ${ }^{2}$ College of Science, Central South University of Forestry and Technology, Changsha, Hunan 410004, China \\ Correspondence should be addressed to Xianjun Li; lxjmu@163.com
}

Received 28 March 2014; Accepted 9 May 2014; Published 25 May 2014

Academic Editor: Li Li

Copyright (C) 2014 Xianjun Li et al. This is an open access article distributed under the Creative Commons Attribution License, which permits unrestricted use, distribution, and reproduction in any medium, provided the original work is properly cited.

Pressure impregnation pretreatment is a conventional method to fabricate wood-based nanocomposites. In this paper, the woodbased luminescent nanocomposites were fabricated with the method and its spectral properties were investigated. The results show that it is feasible to fabricate wood-based luminescent nanocomposites using microwave modified wood and nanophosphor powders. The luminescent strength is in positive correlation with the amount of phosphor powders dispersed in urea-formaldehyde resin. Phosphors absorb UV and blue light efficiently in the range of 400-470 $\mathrm{nm}$ and show a broad band of bluish-green emission centered at $500 \mathrm{~nm}$, which makes them good candidates for potential blue-green luminescent materials.

\section{Introduction}

Researches on luminescent materials have been made for several decades to produce effective fluorescence both commercially and environmentally. The aluminate fluorescence powder has widely served as base material in light-emitting ceramic and luminescent plastic manufacturing industry, with its high transmission capability into luminescence center, light intensity, and considerable quantum efficiency (QE) [1]. Fluorescence doped with rare earth possesses a broad range of advantages, including high luminance, longer afterglow, and better luminous efficiency. They are considered as potential candidates in various applications of fluorescent lamps, LCD, LED, HD plasma TV screens, and identity biomarkers as well as photoelectricity converters [2-4]. When luminescent materials are reduced to nanometer scale, the physical and dynamic properties become distinguished from their previous state. Some studies reported that blue shift occurs in absorption spectrum of nano-manganese oxide $(\mathrm{MnO})$ [5], theoretically caused by small size effect and quantum size effect [6]. $\mathrm{SrAl}_{2} \mathrm{O}_{4}: \mathrm{Eu}^{2+}$ phosphors were used in this study, which put no radical threat or water harm and produce 3 5 higher luminescent intensity than common $\mathrm{ZnS}: \mathrm{Cu}$. Rare earth elements $\mathrm{Sr}$ and $\mathrm{Eu}$ are two main ingredients in this type of phosphor and China holds $80 \%$ appropriation of rare earth reserves. For tailoring and functionally modifying nanometer phosphor aimed at a widespread utilization, the understanding of their bonding mechanism, interaction with solvents, and spectral properties is of great importance.

Wood is one of the traditionally used industrial materials in the world, including a great range of biomass composites such as WPC (wood-plastic composites), inorganicbonded composites, and wood fiber-agricultural fiber composites. However, few investigations were made to study bio-based luminescent nanocomposites. Low permeability of wood species causes some problems for the fabrication of wood-based luminescent nanocomposites. Some literatures reported that intensive microwave pretreatment could generate some microvoids within wood and significantly improve the permeability of wood [7-9]. The main objective of this project is to explore the technical feasibility of manufacturing wood-based luminescent nanocomposites based on the intensive microwave pretreatment and pressure impregnation method and to evaluate the spectral properties of wood-based luminescent nanocomposites. 


\section{Materials and Methods}

2.1. Wood Bleaching. Commercially supplied green poplars were sawn up into test specimen; wood samples with the following dimensions were used for the experiment:

round timber diameters, $150 \mathrm{~mm}$,

timber length, $1.8 \mathrm{~m}$,

sawn timber cross sections, $50 \mathrm{~mm}$ (length) by $30 \mathrm{~mm}$ (width) by $8 \mathrm{~mm}$ (thickness),

$\mathrm{MC}$ range, from 80 to $150 \%$.

In order to lighten wood color to the desired brightness level and insure ideal luminous intensity in later stage, hydrogen peroxide $\left(\mathrm{H}_{2} \mathrm{O}_{2}\right)$ was employed as bleaching agent in terms of constant temperature bath $[10,11]$. First, $3 \mathrm{wt} \%$ $\mathrm{H}_{2} \mathrm{O}_{2}$ (Jihai Chemical Co., Ltd., China) was dissolved in an appropriate amount of distilled water. Then $8.32 \mathrm{~g}$ of sodium silicate $\left(\mathrm{Na}_{2} \mathrm{SiO}_{3}\right)$ (Jihai Chemical Co., Ltd., China) was added into solution as stabilizing agent. To get homogeneous solution, the solution was stirred for 5 minutes using glass rod and remained at $60^{\circ} \mathrm{C}$ for $1.5 \mathrm{~h}$ in an electric-heated thermostatic water bath (HH-S24, Meixiang Automatic Science Instrument Co., Ltd., China).

\subsection{Microwave and Plasma Pretreatment of Bleached Wood.} Intensive microwave pretreatment for bleached poplar was performed in a well-designed microwave heating system including generators with autotuners which supply sufficient microwave energy to the timber and microwave applicators. A microwave applicator is a device in which microwaves interact with timber. Frequency of conveyer was maintained at $45 \mathrm{~Hz}$ during this study (in the range of $60-65 \mathrm{~s}$ duration time). The input power applied to the wood was $6 \mathrm{~kW}$. The test specimen was then oven-dried at $103^{\circ} \mathrm{C}$ to $25 \%$ moisture content.

In order to improve bonding strength between wood and phosphor, the plasma pretreatment was conducted to motivate its surface activation in a plasma processing system (SF-P-1000D-C, Sinophoton Technology, Nanjing, China). As shown in Figure 1, a DC power supply was used to generate plasma. Ar and $\mathrm{O}_{2}$ (high purity, 1:1) were employed as feed gas. The voltage, current and the absolute pressure for the plasma processing equipment was controlled at $425 \mathrm{~V}, 3.28 \mathrm{~A}$ and $38 \mathrm{~Pa}$ during the pretreatment. For all samples, the wood plasma pretreatment was performed for $25 \mathrm{~min}$.

2.3. Pressure Impregnation and Spectrum Measurement. The samples obtained in the experiment were marked as $A-x$, respectively, for the pressure impregnation procedure, where “ $x$ " indicates a phosphor $\left[\left(\mathrm{Ca}_{1.5} \mathrm{Mg}_{0.5} \mathrm{Sr}\right) \mathrm{O}_{3} \cdot \mathrm{Al}_{2} \mathrm{O}_{3} \cdot \mathrm{SiO}_{2}\right.$. $0.05 \mathrm{~B} \cdot 0.01 \mathrm{EuO} \cdot 0.005 \mathrm{Nd}_{2} \mathrm{O}_{3}$ ] solution concentration of 0 , $10,20,40$, and $60 \mathrm{wt} \%$, respectively. Before mixing with urea-formaldehyde resin (UF), the fluorescence powder was grinded to nanoscale (under 100 nanometre) by hand, and the nanofluorescence powder was mechanically mixed with UF resin of $20 \%$ solid content (P\&H Chemicals LLC, China) for $1 \mathrm{~h}$. Then, five sets of specimen dipped in UF resin were simultaneously placed into autoclave; the vacuum remained

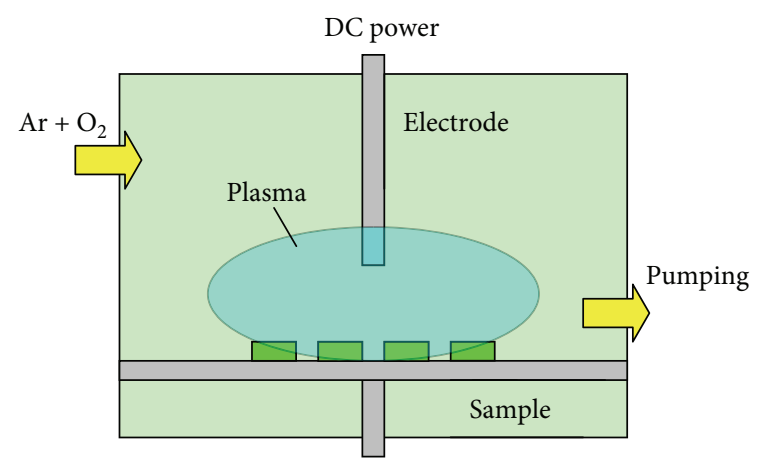

FIGURE 1: Schematic of plasma treatment to microwave pretreated wood.

at $0.08 \mathrm{MPa}$ for $20 \mathrm{~min}$ followed by impregnating procedure of $0.6 \mathrm{MPa}$ for $1 \mathrm{~h}$. Finally, the samples were cooled to room temperature after being oven-dried at $50^{\circ} \mathrm{C}$ to $12 \%$ moisture content and then the spectra for all samples were tested on a fluorescence spectrometer (Otsuka Electronics Co., Ltd, Japan) at room temperature condition.

\section{Results and Discussion}

The measured spectral characteristics for wood-based luminescent nanocomposites with different concentration of luminance are shown in Figures 2(a) and 2(b), respectively. From the figures, it can be found that the peak in excitation spectrum ranges from $220 \mathrm{~nm}$ to $231 \mathrm{~nm}$, in accordance with frequently cited papers reporting excitation maximum of $251 \mathrm{~nm}$ [12-14]. As expected, luminous intensity for $60 \mathrm{wt} \%$ is 13.5 times greater than $0 \mathrm{wt} \%$ composites. This convinces that higher loadings during pressure impregnation will lead to more significant increase of intensity. Additionally, it should be noted that PL intensity (arbitrary unit: a.u) is a common use in spectroscopy field, which represents relative intensity for measurements, ensuring that the plotted data are in good agreement and of great reproducibility [15].

From the emission spectrum data shown in Figure 2(b), it can be seen that luminosity exhibited dramatic rising as increasing concentration of phosphor, especially, brightness of $60 \mathrm{wt} \%$ specimen amounted to $5290 \mathrm{PL}$ intensity (a.u), nearly 10 times of those without fluorescence modification treatment. Furthermore, emission spectral broadband lies from $470 \mathrm{~nm}$ to $550 \mathrm{~nm}$, indicating that bluish-green light can be detected in dark environment.

In general, the aluminate phosphor excited by $\mathrm{Eu}^{2+}$ can produce a relatively high level of long afterglow $[16,17]$. Figure 3 exhibits the afterglow decay curves of specimen of concentration $60 \mathrm{wt} \%$. It can be seen that afterglow decay consists of two periods: rapid decay at the beginning and then a long-lasting decay. Intensity is preserved within the whole measured duration, but decay curve after 315 min almost overlaps to some extent so that it cannot be distinguished. Owing to finite precision accuracy and sensibility of instruments, the long-lasting decay period has been recorded until it timed $585 \mathrm{~min}$. Virtually, emitted light still can be observed by bare eyes after $11 \mathrm{~h}$. 


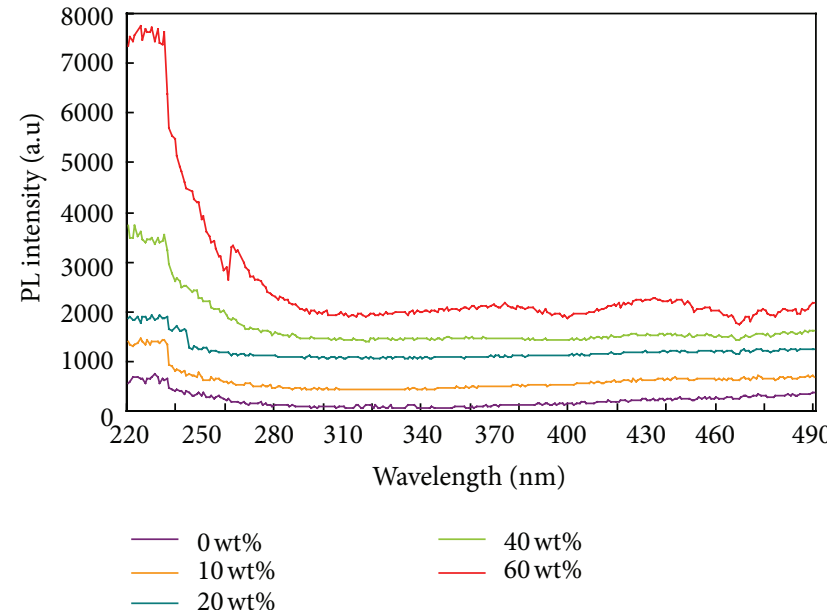

(a)

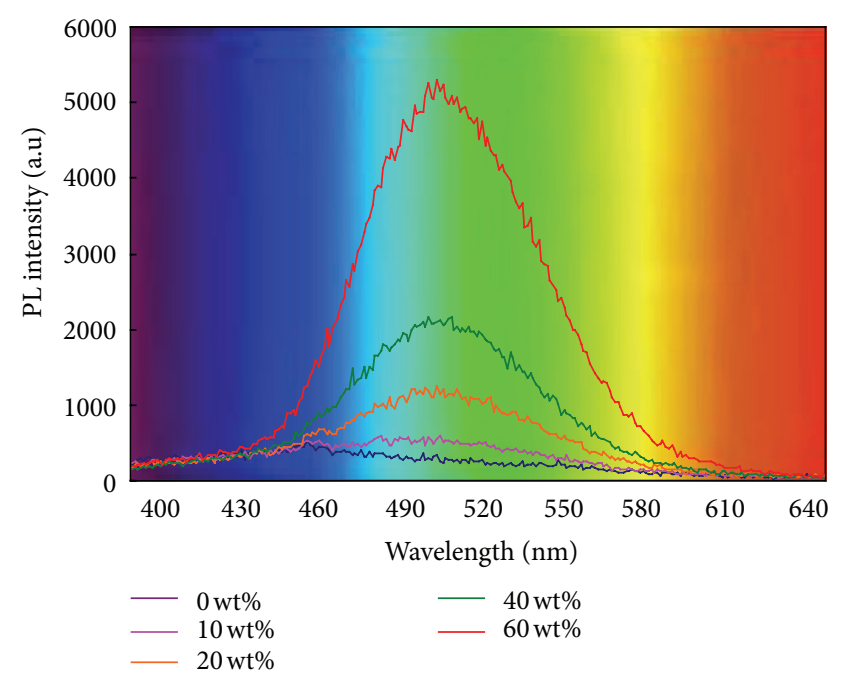

(b)

Figure 2: (a) Excitation $(\lambda \mathrm{em}=513 \mathrm{~nm})$ and $(\mathrm{b})$ emission $(\lambda \mathrm{ex}=254 \mathrm{~nm})$ spectra of nanocomposite at various concentrations of phosphor.

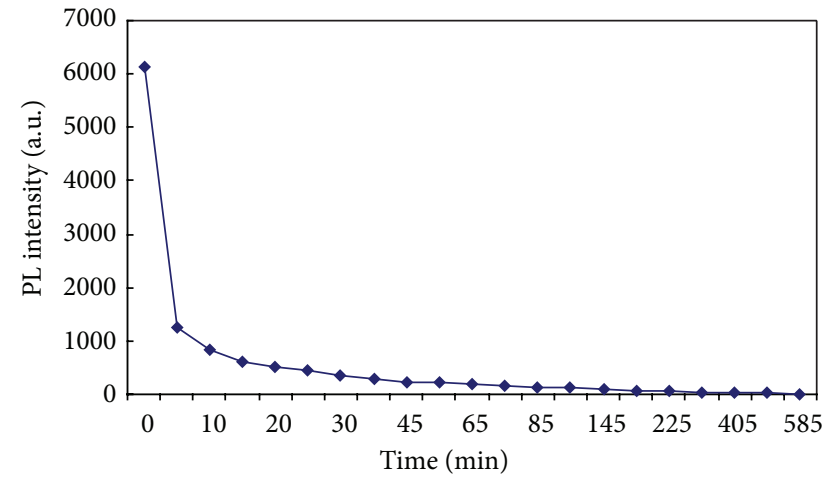

FIGURE 3: Luminescent decay curve (phosphor concentration = $60 \mathrm{wt} \%)$.

The afterglow duration can be evaluated by the curve fitting method, and the original decay curve is fitted to the following equation [18-20]:

$$
I=A_{1} \exp \left(-\frac{t}{\tau_{1}}\right)+A_{2} \exp \left(-\frac{t}{\tau_{2}}\right)
$$

where $I$ is the intensity varying with $t, A_{1}$ and $A_{2}$ are constants, and $\tau_{1}$ and $\tau_{2}$ are attenuation times. Based on decay curve and the equation, the calculated durations are

$$
\tau_{1}=5.26 \mathrm{~min}, \quad \tau_{2}=467.35 \mathrm{~min} .
$$

With the consideration of luminescent material durability in practical applications, we found that wood samples can still generate a relatively strong luminescent intensity with long afterglow which can be observed by eyes after 30 days of trial. It is estimated that active components in fluorescence have not decomposed or deteriorated.

\section{Conclusions}

Based on intensive microwave plasma pretreatment and pressure impregnation method, the wood-based luminescent nanocomposites were fabricated and the spectroscopic properties were investigated in this research. The results show that it is feasible to fabricate wood-based luminescent nanocomposites using microwave modified wood and nanophosphor powders. The luminescent strength is in positive correlation with the amount of phosphor powders dispersed in UF resin. Phosphors absorb UV and blue light efficiently in the range of 400-470 $\mathrm{nm}$ and show a broad band of bluish-green emission centered at $500 \mathrm{~nm}$, which makes them good candidates for potential blue-green luminescent materials. This luminescent material would illuminate for more than eight hours at night after being irradiated by both sunlight and artificial light; therefore, it can be used as directory signs in entertainment sectors and night work constructors could be guaranteed to accurately identify the safety position.

This research result can provide fundamental information to fabricate the wood-based luminescent nanocomposites. Further studies are needed to investigate the optimizational conditions to make wood-based luminescent nanocomposites with longer afterglow in order to manufacture woodbased furniture with luminescent properties in the dark environment.

\section{Conflict of Interests}

The authors declare that there is no conflict of interests regarding the publication of this paper.

\section{Acknowledgments}

Thanks for the support of the Special Fund for Forest Scientific Research in the Public Welfare (no. 201204708), the National Natural Science Foundation of China (no. 
31370564), and the New-Century Training Program Foundation for the Talents by the Ministry of Education of China (NCET-11-0979).

\section{References}

[1] N. Richard and R. O. Kagel, Infrared Spectra of Inorganic Compounds, Academic Press, Waltham, Mass, USA, 1971.

[2] Z. H. Zhang, Q. Huang, X. Zhao, and Z. L. Huang, "Research on solid state physics at the institute of physics," Physica Status Solidi A, vol. 207, no. 12, pp. 2605-2783, 2009.

[3] L. Liu, E. Ma, R. Li, G. Liu, and X. Chen, "Effects of phonon confinement on the luminescence dynamics of $\mathrm{Eu}^{3+}$ in $\mathrm{Gd}_{2} \mathrm{O}_{3}$ nanotubes," Nanotechnology, vol. 18, no. 1, Article ID 015403, 2007.

[4] X. Zhou, J. Qian, Z. Chen et al., "Supramolecular structure, electronic property and stability of Ni-Mg-Al layered double hydroxides," Chemistry - A European Journal, vol. 15, pp. 12331240, 2009.

[5] R. N. Bhargava and D. Gallagher, "Nanophase luminescence particulate material," Physical Review Letters, vol. 72, article 416, 1994.

[6] R. N. J. Bhargava, "Nanoparticles and their use for multifunctional bioimaging," Journal of Luminescence, vol. 70, pp. 851996.

[7] G. Torgovnikov and P. Vinden, "High-intensity microwave wood modification for increasing permeability," Forest Products Journal, vol. 59, no. 4, pp. 84-92, 2009.

[8] X. Li, Y. Zhou, Y. Yan, Z. Cai, and F. Feng, "A single cell model for pretreatment of wood by microwave explosion," Holzforschung, vol. 64, no. 5, pp. 633-637, 2010.

[9] G. Torgovnikov and P. Vinden, "Microwave wood modification technology and its applications," Forest Products Journal, vol. 60, no. 2, pp. 173-182, 2010.

[10] "Wood bleaching," US Patent 2191431 A, Buffalo ElectroOhemical Company, Buffalo, NY, USA, 1940.

[11] S. Peltonen and O. Pikka, "A process for bleaching wood and cellulose pulp intermediates," Tech. Rep. DE 19509401 A1, 1995.

[12] T. Shi, J.Zhou, and Q. H. Sheng, "Photoluminescence properties of nanocrystalline $\gamma-\mathrm{Al}_{2} \mathrm{O}_{3}: \mathrm{Tb}^{3+}$ powder prepared by Sol-gel Method," Bulletin of Chinese Ceramic Socity, vol. 28, no. 2, 2009.

[13] J. L. Zhang and G. Y. Hong, "Progress on the study of nanoscale rare earth lum inescent materials," Chinese Journal of Luminescence, vol. 26, no. 3, 2005.

[14] L. He and W. S. Xu, "Synthesis of rare phosphor $\mathrm{Y}_{2} \mathrm{O}_{3}: \mathrm{Tb}^{3+}$ by Sol-gel method," Journal of Solid State Chemistry, vol. 118, article $163,2000$.

[15] Z. D. Yan, L. D. Sun, C. G. Hu, X. T. Hu, and P. Zeppenfeld, "Factors influencing the ability of fluorescence emission and fluorescence quenching experimental research," Spectroscopy and Spectral Analysis, vol. 32, no. 10, pp. 18-21, 2012.

[16] Q. Song, M. Wu, J. Chen, and J. Chin, "Effect of flux on the properties of $\mathrm{CaAl}_{2} \mathrm{O}_{4} \mathrm{Eu}^{2+}, \mathrm{Nd}^{3+}$ long afterglow phosphor," Journal of Luminescence, vol. 12, no. 2, pp. 144-149, 1991.

[17] Z. Xiao, Light-Storage Luminescent Materials and Their Products, Chemical Industry Press, Beijing, China, 2002 (Chinese).

[18] J. Geng, Z. P. Wu, W. Chen, and L. Luo, "Properties of long afterglow $\mathrm{SrAl}_{2} \mathrm{O}_{4}: \mathrm{Eu}^{2+}, \mathrm{Dy}^{3+}$ phosphor," Journal of Inorganic Materials, vol. 18, no. 2, pp. 480-484, 2003.
[19] F. Kang, Y. Hu, L. Chen et al., "Eu ${ }^{3+}$ Doped $\mathrm{CaWO}_{4}$ - a potential red long afterglow phosphor," Applied Physics B, vol. 107, pp. 833-837, 2012.

[20] X. Song, R. Fu, S. Agathopoulos, H. He, X. Zhao, and X. Yu, "Synthesis of $\mathrm{BaSi}_{2} \mathrm{O}_{2} \mathrm{~N}_{2}: \mathrm{Ce}^{3+}, \mathrm{Eu}^{2+}$ phosphors and determination of their luminescence properties," Journal of the American Ceramic Society, vol. 94, no. 2, pp. 501-507, 2011. 

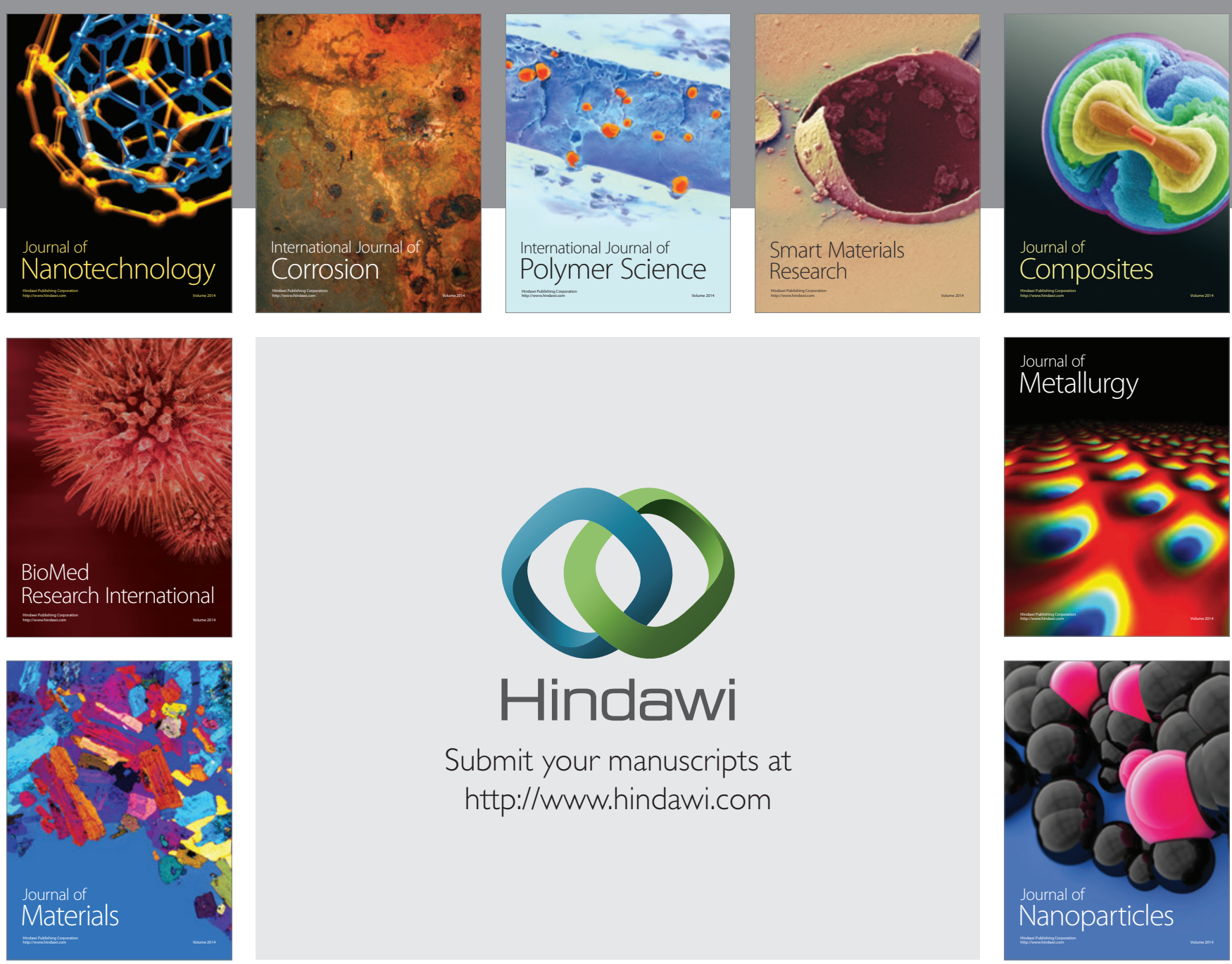

Submit your manuscripts at http://www.hindawi.com
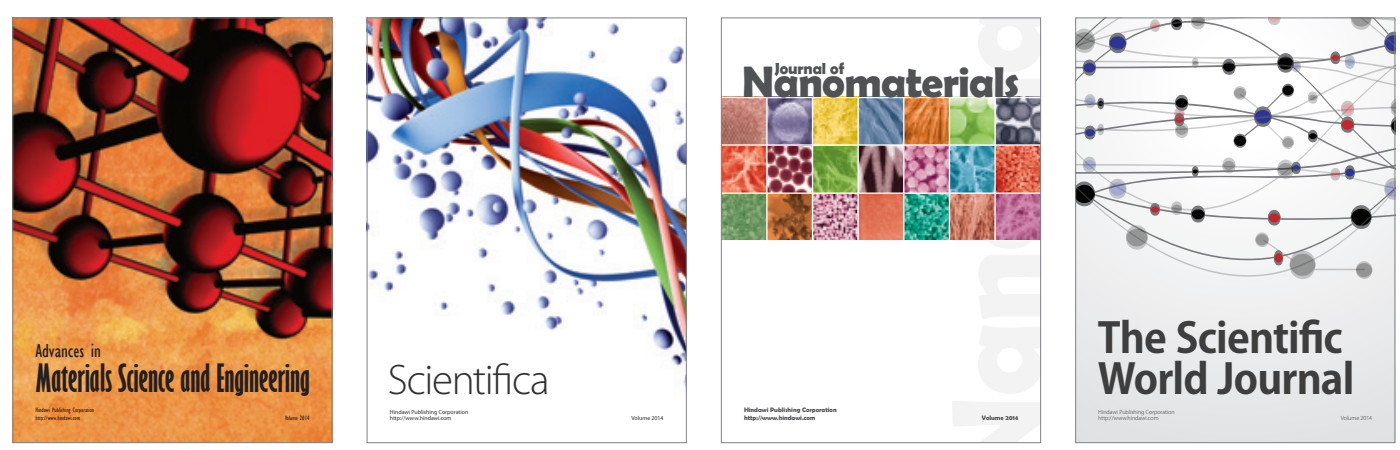

\section{The Scientific World Journal}
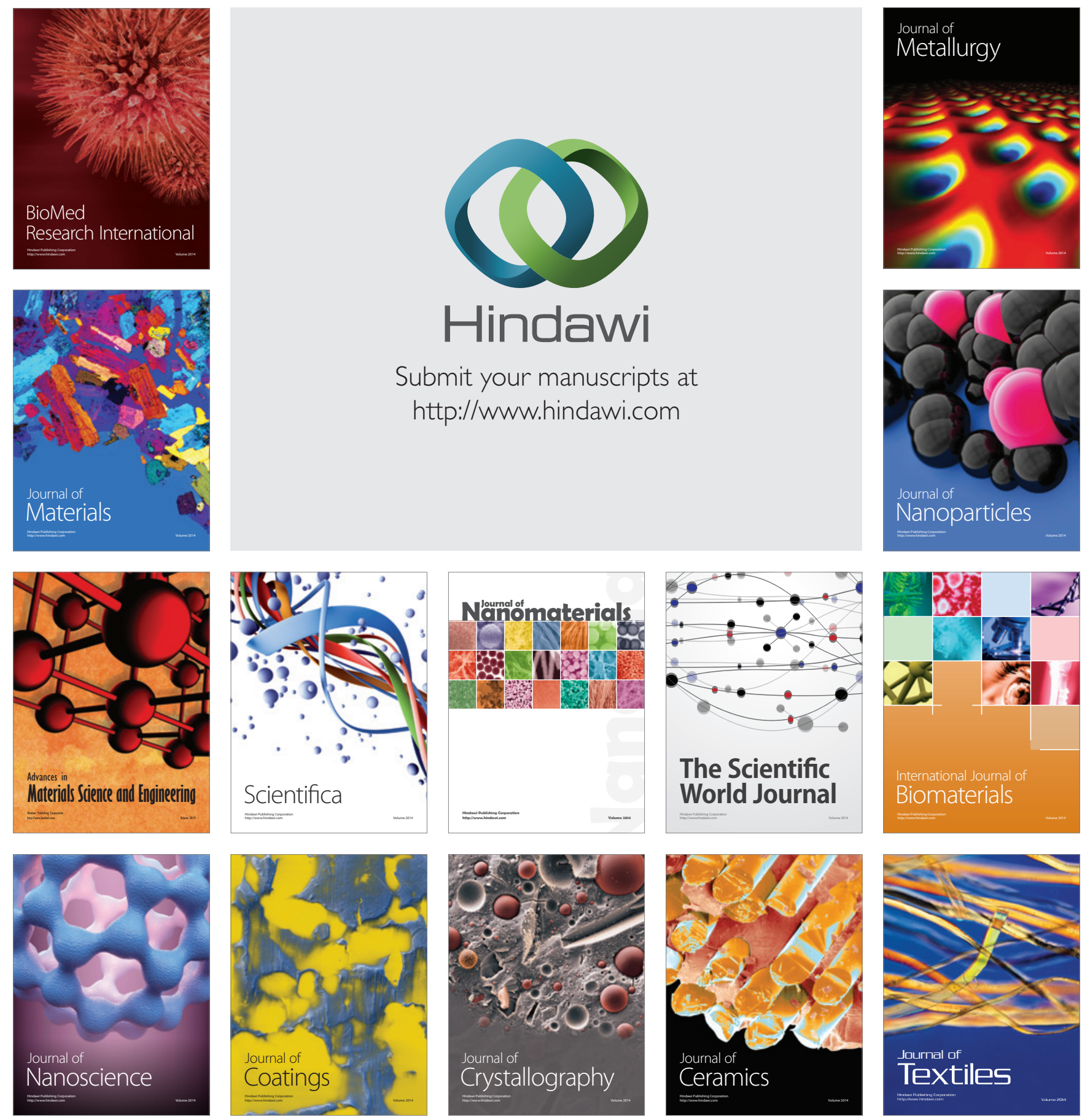